\title{
Global Leadership in Sino-US Cross-border Higher Education
}

\author{
$\mathrm{Xin} \mathrm{Bu}^{1} \&$ Patty Kero ${ }^{1}$ \\ ${ }^{1}$ Department of Educational Leadership, University of Montana, Missoula, Montana, USA \\ Correspondence: Xin Bu, University of Montana, Missoula, MT, USA, 59812. E-mail: xin.bu@umontana.edu
}

Received: September 25, 2019

Accepted: October 23, 2019

Online Published: November 7, 2019

doi:10.5430/ijhe.v8n6p240

URL: https://doi.org/10.5430/ijhe.v8n6p240

\begin{abstract}
Cross-border higher education co-delivered by Chinese and American universities has grown in recent decades. The study focuses on six International Branch Campuses (IBCs) in China, a joint venture between American universities and their Chinese partners. Fourteen Western faculty members who have worked at IBCs were interviewed face-to-face on a one-on-one basis. Three themes were identified in the results: (1) concerns about decision-making, (2) faculty-administrator relationships, and (3) a lack of shared understanding. Implications were provided to leaders from the Chinese partner universities and the home campuses.
\end{abstract}

Keywords: global, leadership, cross-border, international branch campus, Sino-US

\section{Introduction}

\subsection{Research Background}

China and the U.S. have been increasingly engaged in Transnational Education (TNE), particularly in higher education. American universities are interested in diversifying resources and expanding their international influence via TNE, while Chinese universities are looking for partnerships with universities from developed countries to enhance the academic quality in teaching and research. A Blueprint of Educational Modernization in China stated that "a strong nation requires quality education, and quality education is a prerequisite for national development" (Borgos, 2016, p. 275). TNE, in the form of cross-border higher education service delivery, has developed to meet the needs of both sides.

Alam, Alam, Chowdhury and Steiner (2013) as well as Burgess and Berquist (2012) identified multiple TNE delivery modes. The focus of this study is one popular TNE delivery mode, International Branch Campuses (IBC) because "IBCs are new and relatively unexplored expansion of private higher education" (Lane, 2011b, p. 377). For the purpose of this study, an IBC was defined as an off-shore entity of higher education co-established by a home university and its Chinese partner university and operated in the name of both. The IBC is physically located in China. Students earn a degree from the home institution upon successful completion of the course program.

China currently hosts 43 IBCs in partnership with universities from the U.S., Australia, the United Kingdom, France, Germany, Japan, South Korea, Canada, Ireland, Russia, and the Netherlands (C-BERT, 2017). The IBC model requires that foreign institutions partner with government-approved local institutions (McBurnie \& Ziguras, 2007). As of January 2017, 12 IBCs have been established in mainland China by American universities in partnership with Chinese universities (C-BERT, 2017). This partnership must be supervised by the Chinese Ministry of Education (Conning, 2014). IBCs that were selected in this study pertain to American Universities but operate in China. This study is drawn from a larger research project in progress.

\subsection{Problem Statement}

Due to the collaborative nature of IBCs, leadership can be complicated. Typically, representatives from each country's universities co-direct the IBCs. Distinct cultural differences contribute to this complication. Northouse (2013) classified China and the U.S. into Confucian Asia and Anglo clusters. The two clusters are quite different in six dimensions of societal, regional, or local culture originally proposed by Hofstede (2001), which are: power distributed/power-concentrated, group-oriented/self-oriented, consideration/aggression, proactivism/fatalism, generative/replicative, limited relationship/holistic relationship (Dimmock \& Walker, 2005).

The problem is that leadership strategies from both sides may not translate effectively in an IBC context. There are inherent limitations in transferring leadership theories across cultures (House, Dorfman, Javidan, Hanges, \& de Luque, 2014). Leadership from Western culture is not universally applicable to Chinese culture (Wang, 2007). "Successful 
leaders in New York may fail in Beijing or Moscow if they are unable to modify their behaviors to the diverse local backgrounds and expectations" (Gupta, \& Van Wart, 2016, p.23). According to C-BERT data, failing to adapt to the local environment is one of the reasons that some IBCs have closed (Lane, 2011a). Failure to adjust leadership behaviors in different cultural contexts will lead to ineffective leadership.

\subsection{Purpose of this Study}

The purpose of this paper is twofold: (a) to explore how Western faculty members describe leadership at IBCs in China, and (b) to understand desirable leadership and undesirable leadership attributes in global and local contexts. In this study, IBCs present a unique cross-cultural setting. With the results, we aim to understand the influence of culture on leadership behaviors. This paper also contributes to an understanding of effective leadership in cross-border joint higher educational ventures.

\subsection{Theoretical Framework}

This study focused on leadership at IBCs in China. To educational leaders, decision-making is the core of their leadership behavior (Johnson \& Kruse, 2010). Decision-making is "making major organizational choices by understanding the fundamental values and factors involved and by structuring an appropriate decision framework" (Gupta \& Van Mart, 2016, p.365). The fundamental individuals involved in this definition are Western faculty members. Decision-making is concerned about relationships. Leaders build relationships with people with diverse backgrounds (Fullan, 1994). Leaders at IBCs built relationships and interacted with Western faculty members in this study.

Bass (2008) compared two leadership styles in terms of leaders' role in the decision-making process: directive leadership and participative leadership. Directive leadership suggests that leaders play an active role in the decision-making. Directive leaders do not consult or inform followers prior to the decisions. Involvement of the followers in decision-making is minimal. The other style, participative leadership, engages followers in decision-making. Participative leaders listen to the followers and share the final decision with the them. Participative leaders empower followers to actively participate in discussion, problem solving, and decision making. The two leadership styles were reflected in the participants' description on leadership at IBCs in China.

\section{Review of Related Literature}

\subsection{Societal Cultures and Leadership in the U.S. and China}

To date, few studies have explored educational leadership at IBCs. The few studies that have examined leadership in a cross-cultural setting were influenced by Western leadership theories. Likewise, the majority of studies that do exist focused on Western countries, English-speaking countries in particular, given the dominance of English as the global language in knowledge production and dissemination (Walker, Hu, \& Qian, 2012). Similarly, House, Hanges, Javidan, Dorfman, and Gupta (2004) noted that "almost all prevailing theories of leadership and most empirical evidence is North American in character" (p. 56).

Leadership at IBCs in this study took place locally and globally in the process of interactions among IBCs, their cross-border home universities in the U.S, and partner universities in China. Beechler and Javidan (2007) viewed global leadership as a process of influencing individuals, groups, and organizations representing diverse cultural systems. Leadership in a multi-cultural context was noted as dynamic rather than static and may involve accommodation or clash of cultures (Law, 2011). Global leadership contributes to the achievement of the organizations' goals, which in this study, applies to the goals of IBCs.

Understanding the two societal cultures of the home country and the host country is a necessary first step toward understanding the leadership dynamics between these two countries. The Hofstede Model of national culture (2018) utilized six dimensions to compare national cultures of the U.S. and China. The six dimensions are power distance, individualism, masculinity, uncertainty avoidance, long term orientation, and indulgence. In this model, a score scale of 1-100 is applied to indicate the degree of each dimension.

Results of Hofstede's comparison demonstrate that China and the U.S. are distinctly different in the dimension of power distance, individualism, long term orientation, and indulgence. China scores 80 whereas the U.S. scores 40 in power distance, indicating that the Chinese people are more likely to accept inequalities in power distribution. In terms of individualism, China scores 20 and the U.S. scores 91, meaning that Chinese people tend to put group interests before individual interests. It is extremely important to maintain a social network and harmonious relationship within a group in China (Dimmock \& Walker, 2005). With regard to long term orientation, China scores 87 and the U.S. scores 26, which means that Chinese people are interested in planning and investing in the future. A society of long term 
orientation is more likely to delay gratification than enjoy the present (Northouse, 2013). China scores 24 and the U.S. scores 68 in indulgence. Chinese society encourages controlling the gratification of people's desires rather than enjoying leisure time.

Scholars noted the impact of societal culture on leadership between China and the U.S. (Dimmock \& Walker, 2005; Hofstede, 2001; House, Hanges, Javidan, Dorfman, \& Gupta, 2004). Chinese traditions, values, and perceptions are significantly different from those of Western countries (Walker, Hu, \& Qian, 2012). Leadership in China is significantly impacted by Confucian thoughts, tending to establish harmonious relationships and organizational stability and encouraging respecting authority, accepting hierarchy, and demonstrating obedience (Gupta \& Van Wart, 2016). Lowe (2003) compared Chinese and American leadership traditions and identified four distinct dichotomies: (a) individualistic-competitive vs. collectivist-cooperative orientation, (b) democratic vs. autocratic, (c) rationality vs. intuitive orientation, and (d) short-term vs. long-term orientation.

The Global Leadership and Organizational Effectiveness Program (GLOBE) explored leadership in a cross-cultural context. A core leadership concept of GLOBE is implicit leadership theory (ILT) which believes "individuals hold a set of beliefs about the kinds of attributes, personality characteristics, skills, and behaviors that contribute to or impede outstanding leadership" (Dorfman, Hanges, \& Brodbeck, 2004, p. 669). The authors further elaborate that these belief systems shared within a culture shaped individuals' identification of leadership attributes, which has the effect of either contributing to or inhibiting outstanding leadership. There was a statistically significant difference among cultures in leadership beliefs (Hanges, \& Dickson, 2004). The GLOBE study identified the following universal facilitators of leadership effectiveness:

1) Being trustworthy, just, and honest (integrity)

2) Having foresight and planning ahead (charismatic-visionary)

3) Being positive, dynamic, encouraging, motivating, and building confidence (charismatic-inspirational)

4) Being communicative, informed, a coordinator, and team integrator (team builder). (Dorfman, Hanges, \& Brodbeck, 2004, p. 677)

\subsection{Internationalization of Higher Education in China}

The internationalization of higher education in China can be traced back to times as early as the beginning of the 20th century. Chinese people were motivated to internationalize higher education by the notion that learning from the Western models would make China strong (Yang, 2008). Since then, China's higher education has adopted models from Germany, France, and the United Kingdom, as well as Japan (Huang, 2003). However, after the People's Republic of China (PRC) was established in 1949, the Soviet communist model replaced the previously adopted Western model. A highly centralized plan dominated the higher education system. In the years between 1949 and 1978, China's higher education system struggled because it was isolated from the Western world due to overwhelming influence of the Soviet Union (Wang, 2007).

Since 1978, internationalization of higher education in China can be roughly divided into three broad phases. Huang (2003) identified the first two phases: the first from 1978 to 1992, and the second from 1993 to the early 2000s. From the early 2000s to the present constitutes the third phase.

The first phase, followed decades of isolation from English-speaking countries for a few decades leading to an awareness of an urgent need to learn from English-speaking countries. This contributed to more international engagement such as dispatching students, scholars, and faculty members to study abroad, inviting foreign scholars and experts to China, and learning foreign languages, especially English (Huang, 2003).

In the second phase, cooperation between Chinese institutions and foreign institutional partners was encouraged. The Ministry of Education recognized the value of this kind of cooperation by stating that "cooperation with foreign higher education institutions should become an important component in China's education policy" (Huang, 2003, p. 227). As for students and faculty exchange, China faced "brain drain" problems. For example, in 1999, 50\% of graduates from top universities were applying to study abroad (Zweig, Fung \& Han, 2008). To deal with this problem, the central government put much emphasis on encouraging students and scholars to return from overseas studies (Huang, 2003). During this phase, efforts were also made to attract foreign students to study in China, and to internationalize university curricula (Huang, 2003; Yang, 2008).

In the third phase, China obtained membership in the World Trade Organization in 2001 and this rendered a striking impact on China's higher education. After signing its agreement with the General Agreement on Trade in Service (GATS), the Chinese government gradually promoted in-country higher education activity by foreign institutions 
(Yang, 2008). This period saw a dramatic expansion of inbound and outbound student mobility. For example, in 2016, the total number of international students studying in China reached 442,773, representing an increase of $11.35 \%$ compared to 2015, according to the data released by the Ministry of Education of the People's Republic of China (2017).

\section{Method}

This study sought to understand the meaning that the participants ascribe to the phenomenon of leading at IBCs in China by describing their lived experiences from multiple perspectives. The research design was a qualitative, phenomenological strategy of inquiry. The 14 participants were purposefully selected.

The six IBCs are located in the east coast of China: Jiangsu Province, Zhejiang Province, Liaoning Province, and Shanghai. Within these IBCs, there was a two-part and integrated administrative structure involving leaders from both the Chinese and the American universities. The responsibilities of these partnerships required that the American university supported the academic endeavors, whereas the Chinese university provided necessary logistics.

\subsection{Data Collection}

The participants in this study were Western faculty members whose first language is English. Their academic fields, age, professional title, and Chinese language proficiency varied but all participants worked at IBCs in China for more than one semester. The research question guiding this study was: What is leadership at the IBCs in China as described by the Western faculty members? This research question was supported by interview questions that sought to understand the interactions between the participants and leaders at IBCs, the administrators' leadership style, cultural adjustment, decision-making process, and the relationship between the home campus and IBCs in China. The data were collected through semi-structured, one-on- one, face-to-face interviews. The interviews were audio recorded and later transcribed. Nvivo 12 was utilized to assist with managing, exploring, and finding patterns in data analysis.

\subsection{Data Organization}

For the convenience of bringing participants' voices into this study, each participant was assigned a number from 1 to 14 according to the order in which interviews were conducted. This pattern was applied by designating the first participant as P1 and the first statement of a particular participant as S1. Accordingly, participants' statements were coded such that P1, S1 refers to the first statement of the first participant. Identifying information was either removed or modified. Missing or modified information was provided in [] to make the participants' statements complete. To make participants' statements tighter, some information was omitted. The symbol ...... was used to represent omitted information.

\subsection{Ethical Considerations}

This research was approved by the Institutional Review Board (IRB) at the University of Montana prior to data collection. All the information provided by participants during this interview process was kept confidential. Upon the approval of participants, audio recording was used. Participants' identifying information, such as their names, residences, and/or places of employment, as well as all the identity-related information gained during this interview process, was kept confidential, omitted, and does not appear in any reports, presentations, or publications from this study. The participants' names are not associated with the study in any way. Participants have been assigned pseudonyms throughout all the notes. Data were separated from any identifying information.

\section{Findings}

Findings emerged from qualitative data analysis that followed a process of de-contextualization and re-contextualization (Creswell \& Poth, 2018) for a phenomenological study. As a result of this analysis, coding strategies were applied to identify emerging and eventual themes. The identified themes were: (1) concerns about decision-making, (2) faculty-administrator relationships, and (3) a lack of shared understanding.

\subsection{Concerns about Decision-Making}

Concerns arose about inefficient decision-making. Inefficient decision-making was impacted by the IBC partnership model. The decision-making process took longer because it had to be approved by both the home and host institutions. The collaborative but also competitive relationship between both also contributed to inefficiency of decision-making.

Decision-making was also not efficient because reaching consensus was difficult. Mutual understanding of each other's culture is not well developed. Trust as the foundation of this relationship was not sufficient. There was an absence of discussion about cultural differences although faculty perceived that the two cultures dealt with 
communications in a slightly different way. Therefore, it was a challenge to make both sides happy. When disagreement occurred, one side had to compromise which was not easy.

P14, S1: The fact that this is a joint venture between [the home campus and IBC] means that sometimes it can be more complicated to do things because you need to get both sides to agree on certain things.

P7, S1: Sometimes you might have conflict between [the] Chinese and American side about certain things. And I think there, there is sometimes is a bit of a difficulty because I think Americans and Chinese have slightly different ways of dealing with problems.

P10, S1: The biggest issue is the willingness of both partners to compromise. That's not always easy. The communication between different philosophies, or different approaches to education, makes it challenging.

P8, S1: You know that it's very competitive between the Chinese side and American side because they do have meetings together to make mutual decisions. I mean, to make decisions together on some issues. But they're not particularly collegial. You know, they, everybody has a happy face up, a friendly face on. But there's competition always.

Western faculty also experienced frustration because their input was not incorporated into decision-making as much as they expected. Western faculty expressed frustration that decisions made in the U.S. were imposed on them, their input disregarded and the local context ignored. Participants perceived that faculty governance, a common practice in American universities was not adopted at the IBCs at all. Western faculty had little input in decision making. They expected to be involved, particularly when a decision would affect them significantly. One example is a decision made by the home campus to add an extra class workload but the IBC did not need the extra course because the IBC already had low enrollment.

P7, S2: Sometimes decisions are made, ... in the US, which I'm not involved in. So for example, they added an extra course...-- But that was done without our involvement, right?...-- and I think there's a lot [of] frustration because...-we don't really need extra courses, we already have a quite low enrollment, so of course we don't have enough students to fill all the courses we already have.

P11, S1: That [decision-making] has been a genuine complaint. I'm a great fan of faculty governance, and here there's little semblance of it.

P13, S1: They would listen to us, but still they were kind of secretive.

Ineffective decision-making also arose out of insufficient consideration of Chinese students' academic background. Decisions made at the home campuses simply did not work at the IBCs. For instance, accreditation at the IBCs was expected to be the same as the home campuses, but Chinese students' language proficiency levels were different. Because most Chinese students did not grow up in an English-speaking environment, assuming they have equivalent English proficiency and knowledge base as American students was not realistic. Thus, applying the same grading standard was not effective.

P1, S1: There's a lot of things they [home-campus administrators] don't understand over here. Because of accreditation, we're supposed to be the same as them. But you can't grade Chinese [students] the same way, ..., as you would in America. They're at different levels. They expect us to do certain things and we say, "Well, it just won't work here."

P4, S1: We want them [the students] to be successful, and in order for that to take place you need to understand that this is China, it's not the U.S., and certain standards that you set here can not be beneficial to the students in China, and administration in the U.S. does not get it, and that's very frustrating if they do not get it.

P14, S2: Sometimes we had decisions about core structures or things like that, which I can see why it might seem like a good idea if people are sitting in [the home campus] discussing it, but then when you actually try and apply it, then you see that, well, the reality is, well, actually, maybe we tried this five years ago and it didn't work then. But nobody pointed that out at the meeting. Yeah, that's a common problem anywhere, I think, where certain decisions are made without full information on the context.

\subsection{Faculty-Administrator Relationships}

There were three types of faculty-administrator relationships reflected in the communications with between faculty and administrators across both the home campuses and IBCs: positive, absent, and negative. First, communication with leaders who were helpful, collaborative, responsive, innovative, and supportive yielded pleasant feelings. The 
participants especially cared about whether their voices were heard. Western faculty viewed leaders at IBCs who were familiar with Chinese language and culture as a plus.

P4, S2: The deans and executive directors back here in the States, very helpful, I feel like they listen when I speak, not necessarily that they're going to do everything I asked, but the fact that I just feel like I'm heard is important.

P8, S2: My work relationship with the administrators on the American side is very positive. My dean is great to work with, always supportive, very good listener, able to give me back up when I need it.

P10, S2: We're very lucky because our associate dean and dean are very good, and when we do ask a question they're very responsive.

P11, S2: They got somebody who was an academic who not only was familiar with China, but was an expert on Chinese language and he was absolutely wonderful.

P11, S3: The current co-director, I would say is even better. I have an even better relationship with him because he's very innovative, he's supportive, he's encouraging, he's pushing us to do new things.

P12, S1: Let's say that that's how I would describe their leadership style: engaging, effective.

Second, in terms of their relationship with leaders from Chinese partner universities, some participants reported they had little interaction. One of the reasons was Chinese partners were barely involved in academics at IBCs. The participants were largely supervised by their home campuses. Therefore, communications between leaders from the Chinese side and the participants were minimal.

P3, S1: I have a good relationship with only one dean who has come and observe me to teach and we went to lunch actually. But other than that, I know what they look like but I have never had a conversation with them. From the Chinese side I get almost nothing.

P8, S3: This administration of, on the Chinese side, I never had a conversation with them. There's no opportunity for that. I think there's no interest in that. I don't even know some of their job functions.

Third, physical distance caused concerns about faculty-administrator relationships. Some participants reported hierarchy that contributed to inadequate interaction with the home campus officials who only visited IBCs once a year. In the short period of time that the administrators flew over and stayed at the IBCs, most of their time was not spent in communicating with Western faculty but with top leaders at IBCs because of lower hierarchy status of Western faculty. The long distance between China and the U.S. limited their physical time at IBCs. As a result, their short visit did not guarantee their sufficient understanding of the local contexts.

P13, S2: Even the presidents, when they would come [to the IBC], I haven't had too many close interactions. You know, the hierarchy, it's the hierarchy, you know? Even though I was one of the top people at [the IBC], I was not the highest

P8, S4: They fly over, some top administrators, to talk to us about what they do. Well, that's okay, but it doesn't have much to do with what we do.

Some participants described the home campus-IBC relationship as detached. Very often faculty at IBCs were not well-informed about what was going on at the home campus due to an absence of their representatives. As a result, faculty didn't feel they were a part of the home campus or that their concerns were a priority. Delayed communications via email amplified these feelings of neglect.

P3, S2: I feel like it takes them [the home campus] forever to get back to emails.

P10, S3: It's a little disconcerting when ... most of the information we find out is by word of mouth. We're not in any formal chain of command on campus here for the [IBC] side of things. So it's a little frustrating.

P10, S4: The distance does cause some issues. Issues mainly from a communication standpoint as far as what's taking place on campus. We don't find out what other groups find out because we're not in any, we don't have representatives in any administrative meetings on campus. So, it takes a while for us to get information sometimes.

P13, S3: Many of us felt, for years, that we [were] kind of last on the priority list, you know? We kind of felt like outsiders, that we weren't taken that seriously, we didn't have a lot of meetings with the academic dean. We didn't really feel like they knew what was going on.

Some participants were aware of the need to work independently. They were aware that they had to adjust their expectations for timely communication given the physical distance and time difference between the home campus and the IBCs. 
P4, S3: You have to learn to work independently because the time difference between the States and China is usually a 24 hour turnaround. If I send someone an email, and the space of time I may need the answer right away, but I can't get it because that person may be sleeping.

P4, S4: Another thing I've learned, got to be able to function independently if not for a day and adapt and adjust, and if you can't, this is not the place for you and it's not going to work.

\subsection{Lack of Shared Understanding}

As a result of the bifurcated structure, collaboration was made difficult by a lack of shared understanding. IBCs had connections with the Chinese partners and American home campuses. However, the participants observed that both sides lacked an in-depth understanding of IBCs. The Chinese side seemed to have more bureaucratic requirements and did not fully understand the mission and vision of an IBC, whereas the American side did not fully understand the local contexts.

P1, S2: They seem to be more bureaucrats. They're interested in money. Making sure that they get the best bang for the buck.

P1, S3: Foreigners are not here just to attract Chinese students. We're here to contribute and build the university. Big difference in the two.

P4, S5: Some people just go and build a university wherever and not have a full understanding of the culture. Without fully understanding the culture, you need to fully understand the vision that you have for this university and not just a vision as far as, okay, where we are the first year. You need to have a vision like further out, years down the line, and in the future. So I think it is possible to sustain this.

P8, S5: You know, so, I don't think they have clear goals. I don't think the Chinese leadership have clear goals for what they want in content. In fact sometimes I think they don't care what the content is as long as the face looks American, and the curriculum looks American.

P8, S6: The leadership structure is not American. The leadership structure is Chinese and authoritarian and non-consultative. Faculty have no role in governance...., they lack respect for faculty.

\section{Discussion}

The model of joint leadership at IBCs in China reported by participants is consistent with China's policies regulating foreign providers in higher education (Garrett, 2004; Huang, 2003; McBurnie \& Ziguras, 2007). This model intends to engage both partners in a cooperative and collaborative way ensuring an opportunity for input from each. Despite the good intention to involve both parties, the Western faculty participants reported leadership issues.

When describing their relationship with their home campuses, participants frequently mentioned feelings of neglect. Home and host universities' responsibilities differ from case to case. Sometimes an unclear share of responsibilities from each side confused the participants. Participants were not well informed prior to decisions made by home-campus leaders. The participants expected leaders to have genuine interest in engaging faculty members. They hoped to feel like a real part of the organization, rather than feeling detached from their home campus colleagues.

A better understanding of expectations from Western faculty will help administrators support the participants more effectively. Compared to the home campuses, IBC employees rely more on organizational support (Wilkins, Butt \& Annabi, 2017) and smooth faculty-administrator communications were one way this support was provided to participants. Participants expected their voices to be heard and respected. They described leaders who were responsive, easygoing, supportive, and transparent positively. They also appreciated leaders who were good listeners and had integrity.

Western faculty had several suggestions for administrators. Unengaged leadership and non-transparent decision-making was not desirable. Participants experienced frustration when a decision made in the US impacted them tremendously but they were not made aware of how the decision was made. It would be helpful to employ a representative of Western faculty members at the home campus. The representative would serve as a communication bridge between the home campus leaders and participants.

The Western faculty contributed to sustainability of IBCs. Although both partners were motivated to establish an IBC differently, one shared vision is that Western faculty members' involvement will facilitate the sustainability of IBCs in the long term. Their contribution was seen as essential to the success of IBCs. Maintaining comfortable faculty-administrator relationships will increase the likelihood that Western faculty members want to stay and continue their contribution. In the long-term, their contribution will positively shape the future of IBCs in China. 
The findings of this study will inspire future research to investigate administrators' experiences of the home campuses and IBCs. This study provides a piece of the puzzle from the perspectives of Western faculty members but does not represent the holistic picture of leadership in this transnational higher education venture. More research will help reveal a deeper insight into decision-making at IBCs and the home campuses. Further studies will add dimensions to transnational higher education leadership.

\section{Conclusion}

Since IBCs are a phenomenon that emerged only three decades ago in China, partners have made efforts to pursue effective collaboration. An understanding of how to achieve effective leadership in this transnational education venture will promote further cooperation. Insights gained from this study will hopefully generate implications for leaders from Chinese partner university and the home campuses. At IBCs, people from diverse backgrounds and various levels of education work together in China. In order to be successful, leaders must consider this diversity and the local contexts in China when making decisions. Because Western faculty members experienced both positive and negative interactions with home campus leaders, it is important that leaders be aware of what leadership behaviors facilitated the participants' positive experience and what led to negative experiences. Leaders from the home campuses should understand the local conditions in which IBCs operate, including but not limited to Chinese students' academic background, Chinese-speaking contexts, and Chinese local regulations. Given the physical distance between IBCs and the home campuses, it is particularly important to include Western faculty members' voices in home campus decision-making.

Leaders of IBCs need to understand how local conditions and that of the home campus are different. As suggested by Lane (2011a), leaders at IBCs should "find ways to adapt existing policies and practices to best meet those different demands, while still respecting the standards and ethos of the home campus" (p. 9). Leaders from the IBCs also need to understand that Western faculty members live in a foreign country and likely face related difficulties. Local support from Chinese institutional leaders will make a difference. Western faculty members working in a foreign country must anticipate challenges associated with this multi-cultural context and adapt to these challenges.

\section{References}

Alam, F., Alam, Q., Chowdhury, H. \& Steiner, T. (2013). Transnational education: Benefits, threats and challenge. Procedia Engineering, 56, 870 -874. https://doi.org/10.1016/j.proeng.2013.03.209

Bass, M. B. \& Bass, R. (2008). The Bass handbook of leadership: Theory, research, and managerial applications (4th ed., Free Press hardcover ed.). New York: Free Press.

Beechler, S. \& Javidan, M. (2007). Leading with a global mindset. In Javidan, M., Steers, R. \& Hitt, M. (Eds.), Advances in international management, 19, 131-169. Oxford, UK: Elsevier.

Borgos, J. (2016). Addressing sustainable international branch campus development through an organizational structure lens: A comparative analysis of China, Qatar, and the United Arab Emirates. Chinese Education \& Society, 49, 271-287. https://doi.org/10.1080/10611932.2016.1237849

Burgess, P. \& Berquist, B. (2012). Cross-border delivery: projects, programs, and providers. In Cross-border Education Research Team (C-BERT). (2017). Branch campus listing. Retrieved from http://cbert.org/?page_id=34.

Conning, A. S. (2014). Planning a physical presence in China. Global opportunities and challenges for higher education leaders: Briefs on key themes (107-110). Rotterdam, the Netherlands: Sense Publishers.

Creswell, J. W. \& Poth, C. (2018). Qualitative inquiry and research design: Choosing among the five traditions, $\left(4^{\text {th }}\right.$ ed.). Thousand Oaks, CA: Sage.

Cross-border Education Research Team (C-BERT). (2017). Branch campus listing. Retrieved from http://cbert.org/?page_id=34.

Dimmock, C. \& Walker, A. (2005). Educational leadership: culture and diversity. London: Thousand Oaks, CA: Sage.

Dorfman, P. W., Hanges, P. J. \& Brodbeck, F. C. (2004). Leadership and cultural variations. In House, R. J., Hanges, P. J., Javidan, M., Dorfman, P. W. \& Gupta, V. (Eds.). Culture, leadership, and organizations: The GLOBE study of 62 societies. Thousand Oaks, Calif.: Sage.

Fullan, M. (1994). Change Forces: Probing the Depths of Educational Reform, London: the Falmer Press. 
Garrett, R. (2004). Foreign higher education activity in China. International Higher Education, 34, 21-23. https://doi.org/10.6017/ihe.2004.34.7401

Gupta, V. \& Van Wart, M. (2016). Leadership across the globe. New York, NY: Routledge.

Hofstede, G. (2001). Culture's consequences: Comparing values, behaviors, institutions, and organizations across nations (2nd ed.). Thousand Oaks, Calif.: Sage.

Hofstede, G. (2018). The Hofstede Model of national culture. Retrieved from https://www.hofstede-insights.com/models/.

Hanges, P. J. \& Dickson, M. W. (2004). The development and validation of the GLOBE culture and leadership scales. In House, R. J., Hanges, P. J., Javidan, M., Dorfman, P. W. \& Gupta, V. (eds). Culture, leadership, and organizations: The GLOBE study of 62 societies. Thousand Oaks, Calif.: Sage.

House, R. J., Hanges, P. J., Javidan, M., Dorfman, P. W. \& Gupta, V. (2004). Culture, leadership, and organizations: The GLOBE study of 62 societies. Thousand Oaks, Calif.: Sage.

House, R. J.f, Dorfman, P. W., Javidan, M., Hanges, P. J. \& de Luque, M. F. (2014). Strategic Leadership across Cultures: The GLOBE Study of CEO Leadership Behavior and Effectiveness in 24 Countries. Thousand Oaks, Calif.: Sage.

Huang, F. (2003). Policy and practice of the internationalization of higher education in China. Journal of Studies in International Education, 7(3), 225-240. https://doi.org/10.1177/1028315303254430

Johnson, B. \& Kruse, S. (2010). Decision making for educational leaders underexamined dimensions and issues. Albany: State University of New York Press.

Lane, J. E. (2011a). Global expansion of international branch campuses: managerial and leadership challenges. New Directions for Higher Education, 155, 5-17. https://doi.org/10.1002/he.440

Lane, J. E. (2011b). Importing private higher education: International Branch Campuses. Journal of Comparative Policy Analysis: Research and Practice, 13(4), 367-381. https://doi.org/10.1080/13876988.2011.583106

Law, W-W. (2011). Educational leadership and culture in China: dichotomies between Chinese and Anglo-American leadership traditions? International Journal of Educational Development, 32.2(2012), 273-282.

Lowe, S. (2003). Chinese culture and management theory. In Alon, I. (Ed.). Chinese culture, organizational behavior, and international business management. Praeger, Westport, CT, 1-2.

McBurnie, G. \& Ziguras, C. (2007). Transnational education: Issues and trends in offshore higher education. New York, NY: Routledge.

Northouse, P. (2013). Leadership: Theory and practice (6th ed.). Thousand Oaks: Sage.

Walker, A., Hu, R. \& Qian, H. (2012). Principal leadership in China: An initial review. School effectiveness and school improvement, 23(4), 369-399. https://doi.org/10.1080/09243453.2012.678863

Wang, T. (2007). Understanding Chinese Educational Leaders' Conceptions in an International Education Context. International Journal of Leadership in Education, 10(1), 71-88. https://doi.org/10.1080/13603120500445275

Wilkins, S., Butt, M. M \& Annabi, C. A. (2017). The Effects of Employee Commitment in Transnational Higher Education: The Case of International Branch Campuses. Journal of Studies in International Education, 21(4), 295-314. https://doi.org/10.1177/1028315316687013

Yang, R. (2008). Transnational higher education in China: Contexts, characteristics and concerns. Australian Journal of Education, 52(3), 272-286. https://doi.org/10.1177/000494410805200305

Zweig, D., Fung, C. \& Han, D. (2008). Redefining the Brain Drain: China's 'Diaspora Option'. Science, Technology \& Society, 13(1), 1-33. https://doi.org/10.1177/097172180701300101 